ISSN: 2302-8556

E-Jurnal Akuntansi Universitas Udayana

Vol.22.1. Januari (2018): 381-407

DOI: https://doi.org/10.24843/EJA.2018.v22.i01.p15

\title{
Pengaruh Locus Of Control dan Budaya organisasi Berbasis Tri Hita Karana Pada Kinerja Badan Pengawas
}

\author{
Ni Luh Yuli Sudiartini ${ }^{1}$ \\ Ni Putu Sri Harta Mimba ${ }^{2}$
}

\author{
${ }^{1}$ Fakultas Ekonomi dan Bisnis Universitas Udayana (Unud), Bali, Indonesia \\ e-mail:ulickt27@gmail.com /Telp:+6285205503876 \\ ${ }^{2}$ Fakultas Ekonomi dan Bisnis Universitas Udayana (Unud), Bali, Indonesia
}

\begin{abstract}
ABSTRAK
Kinerja seorang badan pengawas Lembaga Perkreditan Desa (LPD) menjadi penting karena badan pengawas bertugas melakukan pengawasan untuk mencegah terjadinya praktik-praktik yang dapat merugikan LPD. Kinerja yang baik dari seorang badan pengawas LPD akan membuat kinerja LPD semakin meningkat, oleh karena itu faktor-faktor yang mempengaruhinya perlu diperhatikan. Faktor individual dan faktor situasional merupakan faktor yang dapat mempengaruhi kinerja dari individu. Faktor individual meliputi jenis kelamin, pengalaman, motivasi, kepribadian, dan locus of control. Sedangkan faktor situasional meliputi kepemimpinan, prestasi kerja, dan budaya organisasi. Penelitian ini bertujuan untuk mendapatkan bukti empiris tentang pengaruh locus of control dan budaya organisasi berbasis tri hita karana pada kinerja badan pengawas LPD sebagai auditor internal di Kabupaten Karangasem. Tri hita karana merupakan budaya yang khusus berkembang di Bali dan diadopsi menjadi budaya organisasi yang digunakan sebagai pedoman dalam berorganisasi salah satunya oleh LPD. Metode pengumpulan data yang digunakan adalah kuesioner. Metode sampling yang digunakan adalah non probability sampling dengan tehnik purposive sampling dan memperoleh 40 sampel dengan 80 responden. Tehnik analisis data yang digunakan adalah Analisis Regresi Linier Berganda. Hasil penelitian menunjukkan bahwa locus of control internal dan budaya organisasi berbasis tri hita karana berpengaruh positif pada kinerja badan pengawas LPD, sehingga semakin tinggi locus of control internal dan semakin baik budaya organisasi berbasis tri hita karana yang diterapkan, maka kinerjanya akan meningkat. Sedangkan locus of control eksternal berpengaruh negatif pada kinerja badan pengawas LPD, sehingga semakin tinggi locus of control eksternal yang dimiliki maka kinerjanya akan menurun.
\end{abstract}

Kata kunci: Locus of control, budaya organisasi, tri hita karana, kinerja.

\begin{abstract}
The performance of supervisory board of a village credit institution (LPD) should be considered because it prevents practices which damage LPD. Good performance of supervisory board of LPD makes the performance increase; therefore the factors that influence it need attention. Individual and situational are the factors can affect the performance of individuals. Individual factors consist of gender, experience, motivation, personality, and locus of control. Meanwhile, situational factors consist of leadership, work achievement, and organizational culture. The aimed of this study was to get empirical evidence regarding the influence of locus control and organization culture based on tri hita karana on the performance of supervisory board of LPD which acts as the internal auditor in Karangasem regency. Tri hita karana is a culture in Bali which develop and appointed into an organization culture which use as a reference in the organization, for example LPD. The data were collected using questionnaire. The sampling method using non probability sampling with purposive sampling technique and 40 samples and 80 respondents were collected. Data were analyzed using multiple linier regressions. The finding of this study showed that the internal locus of control and organizational culture based on tri hita karana
\end{abstract}


Ni Luh Yuli Sudiartini dan Ni Putu Sri Harta Mimba. Pengaruh...

positively impact on the performance of supervisory board of LPD, therefore, when locus of control internal and organization culture based on tri hita karana applied in supervisory board of LPD, the performance was increase. Meanwhile, locus of control external negatively impact on the performance of supervisory board of LPD, therefore, when locus of control external applied in supervisory board of $L P D$, the performance was decrease.

Keywords : Locus of control, organizational culture, tri hita karana, performance

\section{PENDAHULUAN}

Lembaga Keuangan Mikro (LKM) menurut UU No.1 tahun 2003 tentang LKM yaitu lembaga keuangan yang memberikan jasa pengembangan usaha dan pemberdayaan masyarakat melalui pinjaman, pengelolaan simpanan, dan pemberian jasa konsultasi untuk pengembangan usaha. Lembaga Perkreditan Desa (LPD) adalah salah satu LKM yang ada di Provinsi Bali dan berkembang secara pesat. LPD berdasarkan SK Gubernur Bali No. 972 tahun 1984 yang diubah menjadi PERDA Provinsi Bali No. 4 Tahun 2012 yaitu lembaga keuangan milik desa yang melakukan kegiatan usahanya di lingkungan desa.

Karangasem merupakan salah satu kabupaten di Bali yang peranan LPDnya sangat dirasakan oleh krama desanya. Krama desa adalah warga yang menetap dan memiliki ikatan adat istiadat dan budaya. Jumlah LPD di Kabupaten Karangasem sebanyak 190 unit dari 190 Desa Pakraman yang ada dan tersebar di delapan (8) kecamatan dan berstatus aktif serta tidak mengalami permasalahan hukum sebanyak 165 unit. Berdasarkan data yang diperoleh dari Dinas Koperasi dan UKM Kabupaten Karangasem, sampai dengan Juni 2016 aset LPD di Kabupaten Karangasem berjumlah lebih dari Rp 936,1 M dengan penyerapan tenaga kerja 817 orang. Besarnya jumlah aset yang dimiliki, menuntut LPD yang berada Kabupaten Karangasem untuk lebih berhatihati dalam melakukan ekspansi kredit dan mengatur penyebaran risiko agar kredit tidak hanya terpusat pada salah satu kelompok debitur tertentu, sehingga sangat diperlukan adanya pengawasan. 
Pengawasan merupakan rangkaian kegiatan yang terkoordinasi yang dilakukan secara objektif dan berkesinambungan yang akan mempengaruhi kelancaran operasional serta dapat mencegah terjadinya penyimpangan dalam suatu organisasi. Pengawasan ini dapat dilakukan dengan suatu pendekatan yang disebut internal audit dan dilakukan oleh individu dalam organisasi itu sendiri yang disebut dengan auditor internal. Berdasarkan Peraturan Gubernur Bali No 11 Tahun 2013 Bab III Pasal 40, yang bertugas untuk melaksanakan pengawasan intern LPD adalah badan pengawas LPD yang mana diketuai oleh bendesa adat desa setempat.

Kinerja yang baik dari seorang badan pengawas LPD akan membuat kinerja dari LPD semakin meningkat. Melalui hasil pengamatan yang telah dilakukan, diketahui bahwa pengawasan yang telah dilakukan badan pengawas LPD di Kabupaten Karangasem sudah baik. Hal ini bisa dilihat dari pemisahan tugas yang jelas, dimana fungsi dari badan pengawas LPD terpisah dan mandiri dari kegiatan yang diperiksanya. Namun, di Kabupaten Karangasem masih ada LPD yang mengalami permasalahan.

Berdasarkan informasi yang didapat dari Dinas Koperasi dan UKM kabupaten Karangasem, telah terjadi kasus penggelapan dana nasabah di kabupaten Karangasem yang melibatkan pengurus LPD Desa Bungaya pada tahun 2013 yang menyebabkan kerugian LPD hingga Rp 800 juta lebih dan Desa Temega pada tahun 2015 yang menyebabkan kerugian LPD hingga Rp 840 juta. Salah satu faktor penyebab terjadinya kasus ini dapat dikatakan karena kurangnya pengawasan yang dilakukan oleh badan pengawas dari LPD tersebut, sehingga para pelaku tindak kejahatan memiliki celah untuk melakukan penyimpangan. Oleh karena itu tanggung jawab dari badan pengawas LPD ini sangat tinggi karena akan berpengaruh pada kinerjanya. 
Ni Luh Yuli Sudiartini dan Ni Putu Sri Harta Mimba. Pengaruh...

Kinerja yang baik tentunya tidak terbentuk begitu saja, namun ditentukan oleh banyak faktor. Falikhatun dalam Ayudiati (2010) menyatakan bahwa peningkatan kinerja individu pada dasarnya akan dipengaruhi oleh kondisi-kondisi tertentu, yaitu kondisi yang berasal dari dalam individu yang disebut dengan faktor individual dan kondisi yang berasal dari luar individu yang disebut dengan faktor situasional. Faktor individual mencakup jenis kelamin, pengalaman, motivasi, kepribadian, dan locus of control. Sedangkan faktor situasional mencakup kepemimpinan, prestasi kerja, hubungan sosial dan budaya organisasi.

Salah satu faktor penting penentu kinerja individu yang berasal dari dalam diri seseorang adalah locus of control (Rotter, 1966). Hal ini didukung oleh hasil penelitian yang dilakukan oleh Bima (2010), Bunga (2012) dan Putri (2015), menemukan bahwa locus of control berpengaruh pada kinerja individual. Locus of control menurut Rotter (1966) adalah "generalized belief that a person can or cannot control his own destiny" atau cara pandang seseorang terhadap suatu peristiwa apakah dia merasa dapat atau tidak mengendalikan perilaku yang terjadi padanya. Locus of control digolongkan menjadi dua yaitu locus of control internal dan locus of control eksternal. Jika auditor cenderung memiliki locus of control internal yang dipercaya dapat memecahkan masalah yang terjadi dan menciptakan kepuasan pekerjaan sehingga dapat meningkatkan kinerja auditor. Namun, jika auditor memiliki kecenderungan untuk lebih percaya faktor luar sebagai penentu kesuksesan, ia dikatakan memiliki locus of control eksternal (Nasrullah dan Arifuddin, 2014).

Penelitian Alvaro (2008) menunjukkan adanya hubungan yang signifikan antara kinerja auditor dengan locus of control internal. Individu yang memiliki locus of control internal cenderung berusaha lebih keras ketika ia meyakini bahwa usahanya tersebut 
memberikan hasil. Hasil penelitian oleh Putri (2015) juga menemukan bahwa auditor yang memiliki locus of control internal mempunyai kepuasan kerja yang lebih tinggi dibandingkan dengan auditor yang memiliki locus of control eksternal. Penelitian yang dilakukan oleh Ceacilia et al. (2015), menyebutkan bahwa locus of control eksternal berpengaruh positif pada penerimaan perilaku disfungsional audit, jadi dapat disimpulkan bahwa auditor yang memiliki kecenderungan locus of control eksternal dalam dirinya akan lebih memberikan toleransi disfungsional audit, sehingga akan menurunkan kinerjanya.

Salah satu faktor situasional yang memiliki pengaruh penting pada kinerja individual adalah budaya organisasi. Budaya organisasi adalah asumsi dasar, nilai-nilai, keyakinan, perilaku dan sikap bersama yang dianut organisasi yang dijadikan acuan dalam memahami lingkungan internal dan eksternal demi tercapainya tujuan organisasi (Bharadwaj dan Schein dalam Winata dkk. (2015). Budaya organisasi juga dianggap memiliki pengaruh pada kinerja auditor, karena budaya organisasi mengarahkan individu dalam hubungan kerja sehari-hari dan menuntun individu tentang bagaimana seharusnya berperilaku dan berkomunikasi serta memandang masa depan (Ebru, 2014). Hal ini senada dengan hasil penelitian Nenni (2014), yang menyatakan bahwa budaya organisasi berpengaruh positif pada kinerja auditor.

Khusus di daerah Bali berkembang budaya organisasi yang mengadopsi sistem kepercayaan tri hita karana sebagai pedoman dalam menjalankan suatu organisasi, seperti subak, desa adat, hotel, instansi pemerintahan dan LPD. Tri hita karana merupakan filosofi yang sekaligus menjadi konsep kehidupan dan sistem kepercayaan masyarakat Bali yang mengedepankan prinsip-prinsip kebersamaan, keselarasan, dan keseimbangan antara tujuan ekonomi, pelestarian lingkungan dan budaya, estetika dan 
Ni Luh Yuli Sudiartini dan Ni Putu Sri Harta Mimba. Pengaruh...

spiritual (Adiputra et al. 2014). Konsep tri hita karana merupakan konsep harmonisasi hubungan yang selalu dijaga masyarakat Hindu Bali meliputi : parahyangan (hubungan manusia dengan Tuhan), pawongan (hubungan antar-manusia), dan palemahan (hubungan manusia dengan lingkungan) yang bersumber dari kitab suci agama Hindu Baghawad Gita (Riana, 2010).

Badan pengawas LPD sebagai auditor internal diharapkan dapat menerapkan ajaran tri hita karana sebagai modal utama dalam prinsip hidupnya. Ketika melakukan proses pengawasan, budaya organisasi berbasis tri hita karana ini diharapkan dapat memberikan arah atau pedoman berperilaku bagi seorang badan pengawas dalam organisasi, dimana badan pengawas sebagai auditor internal dalam LPD tersebut tidak dapat berperilaku sekehendak hatinya melainkan harus menyesuaikan diri dengan siapa dan dimana mereka berada.

Pratiwi, dkk. (2016) menyatakan bahwa, semakin baik budaya organisasi yang diterapkan oleh auditor maka kinerja auditor akan semakin baik. Budaya organisasi yang kuat akan memicu auditor untuk berpikir, berperilaku, dan bersikap sesuai dengan nilai-nilai organisasi yang meliputi profesionalisme, percaya pada rekan, keteraturan dan integrasi, sehingga kesesuaian ini dapat mendorong auditor untuk meningkatkan kinerjanya menjadi lebih baik, dalam mewujudkan kualitas, kuantitas, ketepatan, dan kemandirian kinerjanya.

Mengacu pada uraian latar belakang masalah diatas, pokok permasalahan dalam penelitian ini yaitu : 1) Bagaimanakah pengaruh locus of control internal pada kinerja badan pengawas LPD? 2) Bagaimanakah pengaruh locus of control eksternal pada 
kinerja badan pengawas LPD? 3) Bagaimanakah pengaruh budaya organisasi berbasis tri hita karana pada kinerja badan pengawas LPD?

Tujuan dari penelitian ini yaitu : 1) Untuk mengetahui dan mendapatkan bukti secara empiris mengenai pengaruh locus of control internal pada kinerja badan pengawas LPD. 2) Untuk mengetahui dan mendapatkan bukti secara empiris mengenai pengaruh locus of control eksternal pada kinerja badan pengawas LPD. 3) Untuk mengetahui dan mendapatkan bukti secara empiris mengenai pengaruh budaya organisasi berbasis tri hita karana pada kinerja badan pengawas LPD.

Kegunaan dari penelitian ini yaitu : 1) Kegunaan teoretis, hasil penelitian ini memberikan bukti empiris mengenai teori atribusi yang digunakan mampu menjelaskan bahwa locus of control dan budaya organisasi berbasis tri hita karana mempengaruhi kinerja dari badan pengawas LPD. 2) Kegunaan praktis, hasil penelitian ini dapat memberikan kontribusi praktis bagi badan pengawas LPD sebagai auditor internal terutama dalam mengetahui faktor-faktor yang dapat mempengaruhi kinerjanya.

Penyebab atau motif perilaku individu dapat dijelaskan melalui teori atribusi. Teori ini menjelaskan mengenai kombinasi antara kekuatan internal dan eksternal yang dapat menentukan perilaku dari individu (Lubis, 2009:90). Kekuatan internal mengacu pada aspek individu seperti sifat pribadi, persepsi diri, kemampuan dan motivasi. Sedangkan kekuatan eksternal mengacu pada lingkungan seperti kondisi sosial, nilai sosial, dan pandangan masyarakat. Oleh karena itu, teori atribusi digunakan sebagai dasar untuk mengkaji faktor-faktor (locus of control dan budaya organisasi berbasis tri hita karana) yang mempengaruhi kinerja badan pengawas LPD.

Bab III Pasal 40 dalam PERGUB Bali No 11 Tahun 2013, menjelaskan yang dimaksud dengan pengawas internal dalam LPD adalah badan pengawas yang dibentuk 
Ni Luh Yuli Sudiartini dan Ni Putu Sri Harta Mimba. Pengaruh...

oleh desa Pakraman yang bertugas untuk melakukan pengawasan terhadap pengelolaan LPD. Badan pengawas ini terdiri dari ketua dan sekurang-kurangnya dua (2) orang anggota. Ketua dari badan pengawas ini dijabat oleh bendesa pakraman dan untuk anggotanya dipilih oleh krama desa setempat dimana LPD ini berada dan tidak dapat merangkap menjadi seorang pengurus LPD.

Amstrong \& Baron dalam Nasrullah et al. (2013) menyatakan kinerja adalah hasil kerja yang memiliki hubungan yang kuat dengan tujuan strategis organisasi, kepuasan pelanggan, dan memberikan kontribusi bagi perekonomian. Menurut Putra dan Latriani (2016) kinerja auditor merupakan tindakan atau pelaksanaan tugas pemeriksaan yang telah diselesaikan oleh auditor dalam kurun waktu tertentu. Dari definisi tersebut dapat diketahui bahwa unsur-unsur yang terdapat dalam kinerja terdiri dari hasil-hasil fungsi pekerjaan, pencapaian tujuan organisasi dan periode waktu tertentu. Apabila individu dapat melaksanakan tugas dan tanggungjawab yang diberikan dengan baik dan sesuai dengan harapan organisasinya, maka dapat dikatakan bahwa individu tersebut memiliki kinerja atau prestasi yang baik pula (Sanjiwani dan Wisadha, 2015).

Locus of control dapat diartikan sebagai pikiran seseorang atas keyakinan dirinya / kekuatan atas atau dari atau luar dirinya / kontrol atas dirinya yang berpengaruh dalam situasi positif dan negatif yang terjadi selama hidupnya (Sardogan dalam Rana et al. 2011). Sedangkan menurut Zubir (2014), locus of control adalah persepsi seseorang tentang sumber nasibnya yang disebabkan oleh dirinya atau faktor dari luar dirinya. Engko dan Gundono (2007) menyatakan bahwa locus of control dibedakan menjadi dua tipe, yaitu locus of control internal dan locus of control eksternal. 
Locus of control internal yakni suatu kondisi dimana individu-individu meyakini bahwa mereka dapat mengendalikan apa yang terjadi pada dirinya. Individu yang memiliki locus of control internal percaya bahwa reaksi yang ditimbulkan adalah sesuatu yang disebabkan oleh sikap dari individu itu sendiri (Vishal, 2013), sehingga semakin tinggi locus of control internal auditor maka akan meningkatkan kinerja dari auditor dalam melaksanakan tugas-tugasnya. Selain itu, auditor yang memiliki locus of control internal akan memiliki kelebihan dalam mengolah data dan menyampaikan informasi, sehingga tidak akan menemukan kesulitan dalam melaksanakan tugas dan memiliki kontribusi positif pada kinerjanya (Ceacillia et al. 2015; Margie dkk. 2016). Penelitian yang dilakukan oleh Ayudiati (2010) menemukan bahwa locus of control berpengaruh positif dan signifikan terhadap kinerja karyawan. Hasil penelitian yang sama juga ditemukan oleh Sanjiwani dan Wisadha (2015), dimana dari penelitian ini ditemukan bahwa ada pengaruh positif dari locus of control pada kinerja auditor di Kantor Akuntan Publik (KAP) Provinsi Bali. Berdasarkan penjelasan dan hasil penelitian sebelumnya, maka dapat disimpulkan bahwa locus of control internal berpengaruh pada kinerja individu. Hipotesis yang dapat dikemukakan adalah sebagai berikut :

$\mathrm{H}_{1}$ : Locus of control internal berpengaruh positif pada kinerja badan pengawas LPD.

Locus of control eksternal yakni suatu kondisi dimana individu-individu meyakini bahwa apa yang terjadi pada dirinya dikendalikan oleh kekuatan luar seperti nasib dan keberuntungan. Individu dengan locus of control eksternal akan merasa enggan merubah perilakunya, karena individu tersebut merasa bahwa bukan dirinya yang menentukan keberhasilannya (Kurt et al. 2012). Selain itu, Muslim (2014) menyatakan bahwa auditor yang memiliki locus of control eksternal cenderung memiliki 
Ni Luh Yuli Sudiartini dan Ni Putu Sri Harta Mimba. Pengaruh...

keinginan untuk bertindak tidak jujur atau melakukan manipulasi untuk mencapai tujuan pribadi sehingga akan mempengaruhi kinerjanya. Locus of control eksternal yang dimiliki oleh seorang auditor cenderung membawa dampak negatif pada kinerjanya (Rita et al. 2016). Hal yang sama juga ditemukan dari hasil penelitian yang dilakukan oleh Kusnadi (2015) yang menemukan bahwa locus of control eksternal memiliki pengaruh negatif pada kinerja auditor di KAP Provinsi Bali. Berdasarkan penjelasan dan hasil penelitian sebelumnya, maka dapat disimpulkan bahwa locus of control eksternal berpengaruh negatif pada kinerja individu. Hipotesis yang dapat dikemukakan adalah sebagai berikut :

$\mathrm{H}_{2}$ : Locus of control eksternal berpengaruh negatif padahkinerja badan pengawas LPD.

Budaya organisasi merupakan elemen yang dapat membuat anggota dari sebuah organisasi agar tetap sejalan sehingga tujuan organisasi dapat tercapai (Adewale \& Anthonia, 2013; Uddin et al. 2013). Budaya organisasi yang positif dan kuat akan mampu membuat anggota organisasi untuk bekerja dengan baik sehingga akan mencapai kinerja yang maksimal sebaliknya budaya organisasi yang negatif dan lemah akan membuat kinerja dari anggota organisasi mengalami penurunan (Ehtesham et al. 2011).

Budaya organisasi merupakan salah satu bagian dari faktor situasional yang dapat menentukan kinerjahdari individu. Salah satu budaya yang perlu diperhatikan adalah budaya lokal seperti di daerah Bali yang mengadopsi budaya tri hita karana sebagai budaya organisasi. Budaya tri hita karana adalah budaya kearifan lokal yang dimiliki oleh masyarakat Bali yang menekankan bahwa kesejahteraan dapat dicapai dengan tiga dimensi kebersamaan (Sujana et al. 2014) dan telah diadopsi menjadi budaya organisasi. Budaya ini memberikan panduan tentang bagaimana individu harus 
bersikap terhadap tiga hal agar mencapai kesejahteraan berkelanjutan yaitu, hubungan manusia dengan Tuhan (parahyangan), hubungan manusia dengan manusia (pawongan), dan hubungan manusia dengan lingkungannya (palemahan) (Agung dalam Surya, 2014). Penelitian sebelumnya mengenai tri hita karana yang diadopsi menjadi budaya organisasi telah dilakukan oleh Gunawan (2011) yang meneliti tentang pengaruh tri hita karana yang diadopsi sebagai budaya organisasi pada kinerja organisasi dan mendapatkan hasil bahwa budaya tri hita karana berpengaruh terhadap kinerja. Penelitian juga dilakukan oleh Saputra (2012) dan Adiputra et al. (2014), yang menemukan hasil bahwa budaya tri hita karana yang diadopsi menjadi budaya organisasi berpengaruh positif dan signifikan terhadap kinerja manajemen. Berdasarkan penjelasan dan hasil penelitian sebelumnya, maka dapat disimpulkan bahwa budaya organisasi memiliki pengaruh terhadap kinerja dari individu. Hipotesis yang dapat dikemukakan sebagai berikut :

$\mathrm{H}_{3}$ : Budaya organisasi berbasis tri hita karana berpengaruh positif pada kinerja badan pengawas LPD.

\section{METODE PENELITIAN}

Pendekatan yang digunakan dalam penelitian ini adalah pendekatan kuantitatif berbentuk asosiatif, yang digunakan untuk meneliti populasi atau sampel tertentu dengan tujuan menguji hipotesis yang telah ditetapkan. Berikut merupakan desain penelitian yang memperlihatkan model penelitian yang akan di lakukan :

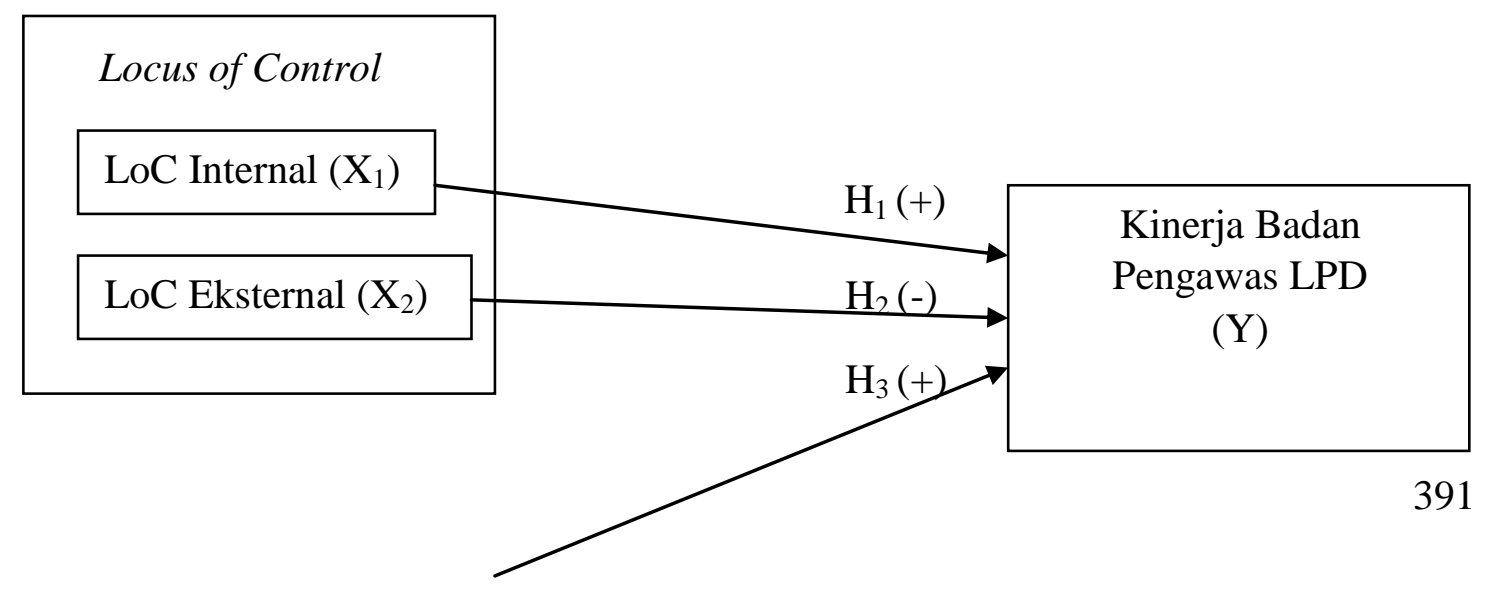


Ni Luh Yuli Sudiartini dan Ni Putu Sri Harta Mimba. Pengaruh...

Budaya Organisasi berbasis Tri Hita Karana

$\left(\mathrm{X}_{3}\right)$

Sumber : Data Diolah, 2016

\section{Gambar 1. Desain Penelitian}

Lokasi dari penelitian ini mengambil tempat yakni pada LPD di Kabupaten Karangasem, dengan obyek penelitiannya kinerja dari badan pengawas LPD sebagai auditor internal yang dijelaskan oleh pengaruh locus of control dan budaya organisasi berbasis tri hita karana. Variabel yang digunakan dalam penelitian ini yaitu variabel bebas (locus of control internal, locus of control eksternal dan budaya organisasi berbasis tri hita karana) dan variabel terikat (kinerja badan pengawas LPD).

Data yang digunakan dalam penelitian ini adalah data kuantitatif yang berupa hasil kuesioner jawaban dari para responden tentang variabel yang diujikan. Sedangkan berdasarkan sumbernya data yang digunakan adalah data primer yang diperoleh dari jawaban para responden terhadap pernyataan yang terdapat pada kuesioner.

Populasi dari penelitian ini yakni LPD yang terdaftar pada Dinas Koperasi dan UKM Kabupaten Karangasem, berstatus aktif dan tidak mengalami permasalahan hukum yang berjumlah 165 unit. Purposive sampling dipilih sebagai metode penentuan sampel dengan kriteria yakni LPD yang memiliki jumlah aset peringkat lima (5) besar di setiap kecamatan, sehingga diperoleh jumlah sampel sebanyak 40 LPD di Kabupaten Karangasem. Dipilihnya lima (5) sampel dengan aset terbesar di setiap kecamatan karena semakin tinggi nilai aset yang dimiliki maka akan semakin tinggi pula tingkat pertanggungjawaban LPD disetiap kecamatan terhadap dana masyarakat yang dikelola. Daftar sampel penelitian dapat dilihat pada Tabel 1.

\section{Tabel 1.}


Daftar Sampel Penelitian

\begin{tabular}{cll}
\hline No & Kecamatan & \multicolumn{1}{c}{ Nama LPD } \\
\hline 1 & Manggis & LPD Manggis, Sengkidu, Gegelang, Nyuh Tebel, dan Angantelu. \\
2 & Sidemen & LPD Telun Wayah, Sukahet, Sangkan Gunung, Delod Yeh, dan \\
& Tebola. \\
3 & Rendang & LPD Rendang, Menanga, Nongan, Pesaban dan Besakih \\
4 & Selat & LPD Duda, Sogra, Selat, Sebudi dan Uma Cetra \\
5 & Karangasem & LPD Bugbug, Jasri, Tumbu, Perasi dan Timbrah. \\
6 & Abang & LPD Kesimpar, Ngis, Datah, Tukad Besi, dan Purwa Ayu \\
7 & Kubu & LPD Behulu, Tigaron, Tianyar, Kreblahan, dan Ban \\
8 & Bebandem & LPD Sibetan, Bebandem, Macang, Komala dan Nangka \\
\hline
\end{tabular}

Sumber : Data Diolah, 2016

Pengumpulan data dalam penelitian ini menggunakan metode kuesioner yang dilakukan dengan cara memberikan sejumlah pernyataan kepada responden. Hasil dari kuesioner ini diukur menggunakan skala Likert 4 poin. Penelitian ini menggunakan Method Succesive of Interval (MSI) untuk mentransformasikan data ordinal (skor kuesioner) menjadi data interval. Untuk pengolahan data digunakan alat bantu yakni program SPSS for windows.

Untuk memperoleh data yang benar-benar menggambarkan fenomena, dilakukan pengujian pada instrumen penelitian yaitu dilakukan uji validitas dan reliabilitas. Instrumen penelitian dikatakan valid apabila nilai $r$ hitung $>r$ kritis $(0,30)$ (Ghozali, 2013 : 52-55) dan instrumen dikatakan reliabel apabila memiliki nilai cronbachs's alpha >0,60. Selain itu dilakukan pula pengujian asumsi klasik yang terdiri dari uji normalitas data, uji multikolinearitas, dan uji heteroskedastisitas.

Analisis regresi linier berganda digunakan dalam penelitian ini untuk mengetahui pengaruh dari variabel bebas $\left(\mathrm{X}_{1}, \mathrm{X}_{2}, \mathrm{X}_{3}\right)$ pada variabel terikat $(\mathrm{Y})$. model regresi diformulasikan sebagai berikut :

$$
\mathrm{Y}=\alpha+\beta_{1} \mathrm{X}_{1}+\beta_{2} \mathrm{X}_{2}+\beta_{3} \mathrm{X}_{3}+\mathrm{e}
$$

Keterangan :

$\mathrm{Y} \quad=$ kinerja badan pengawas LPD

$\alpha \quad=$ konstanta 
$\beta_{1}-\beta_{3}=$ koefisien regresi variabel $X_{1}, X_{2}, X_{3}$

$\mathrm{X}_{1} \quad=$ locus of control internal

$\mathrm{X}_{2} \quad=$ locus of control eksternal

$\mathrm{X}_{3} \quad=$ budaya organisasi berbasis tri hita karana

e $\quad=$ error

Analisis regresi linier berganda terdiri dari uji kelayakan model (uji F) yang bertujuan untuk mengetahui apakah model regresi layak untuk diuji, uji koefisien determinasi $\left(\mathrm{R}^{2}\right)$ bertujuan mengukur seberapa jauh kemampuan model dalam menerangkan variasi variabel independen, dan uji hipotesis (uji t) yang bertujuan untuk mengetahui seberapa jauh pengaruh dari variabel independen secara independen dalam menerangkan variasi variabel dependen.

\section{HASIL DAN PEMBAHASAN}

Responden dalam penelitian ini adalah badan pengawas LPD di Kabupaten Karangasem, dimana setiap LPD dikirimi dua kuesioner yang ditujukan kepada ketua badan pengawas dan satu anggota badan pengawas LPD sehingga kuesioner yang disebar sebanyak 80 kuesioner. Dari 80 kuesioner tersebut, kembali sebanyak 72 kuesioner dan digunakan untuk analisis data.

Statistik deskriptif menyajikan informasi mengenai karakteristik dari variabel penelitian mengenai jumlah amatan, nilai minimum, nilai maksimum, mean dan standard deviation. Hasil statistik deskriptif dapat dilihat pada Tabel 2.

Tabel 2.

Hasil Uji Statistik Deskriptif

\begin{tabular}{lccccc}
\hline \multicolumn{1}{c}{ Variabel } & N & Min & Max & Mean & $\begin{array}{c}\text { Std. } \\
\text { Deviation }\end{array}$ \\
\hline Kinerja Badan Pengawas LPD & 72 & 12,00 & 44,21 & 33,6019 & 10,42190 \\
Locus of Control Internal & 72 & 4,00 & 15,71 & 11,4117 & 3,22499 \\
Locus of Control Eksternal & 72 & 5,45 & 18,35 & 10,9374 & 3,22634 \\
Budaya Organisasi berbasis Tri Hita & 72 & 12,00 & 45,56 & 33,9792 & 9,96465 \\
\hline
\end{tabular}


Sumber : Data Diolah, 2017

Berdasarkan Tabel 2 variabel kinerja badan pengawas LPD nilai terendahnya adalah sebesar 12,00 dan nilai tertinggi sebesar 44,21 nilai mean variabel kinerja badan pengawas LPD adalah sebesar 33,6019 dengan nilai standar deviasi adalah sebesar 10,42190, yang berarti penyimpangan kinerja badan pengawas LPD tersebut dari rataratanya adalah sebesar 10,42190 .

Variabel locus of control internal nilai terendahnya adalah sebesar 4,00 dan nilai tertinggi adalah sebesar 15,71 nilai mean variabel locus of control internal adalah sebesar 11,4117 dengan nilai standar deviasi adalah sebesar 3,22499, yang berarti penyimpangan locus of control internal tersebut dari rata- ratanya adalah sebesar 3,22499 .

Variabel locus of control eksternal nilai terendahnya adalah sebesar 5,45 dan nilai tertinggi adalah sebesar 18,35 nilai mean variabel locus of control eksternal adalah sebesar 10,9374 dengan nilai standar deviasi adalah sebesar 3,22634, yang berarti penyimpangan locus of control eksternal tersebut dari rata- ratanya adalah sebesar 3,22634. Variabel budaya organisasi berbasis tri hita karana nilai terendahnya adalah sebesar 12,00 dan nilai tertinggi adalah sebesar 45,56 nilai mean variabel budaya organisasi berbasis tri hita karana adalah sebesar 33,9792 dengan nilai standar deviasi adalah sebesar 9,96465, yang berarti penyimpangan budaya organisasi berbasis tri hita karana tersebut dari rata-ratanya adalah sebesar 9,96465.

Uji validitas dilakukan untuk menguji apakah pernyataan dalam setiap variabel yang digunakan dapat mengukur apa yang seharusnya diukur. Hasil dari pengujian validitas dapat dilihat pada Tabel 3. Berdasarkan data pada Tabel 3 dapat dilihat bahwa dari setiap instrumen pertanyaan pervariabel memiliki nilai koefisien korelasi $>\mathrm{r}$ kritis 
Ni Luh Yuli Sudiartini dan Ni Putu Sri Harta Mimba. Pengaruh...

$=0,30$. Hal ini berarti instrumen pertanyaan di setiap variabel dalam penelitian adalah valid dan dapat dipakai untuk menguji hipotesis penelitian.

Tabel 3.

Hasil Uji Validitas

\begin{tabular}{|c|c|c|c|}
\hline Variabel & Item Pertanyaan & Koefisien Korelasi & Keterangan \\
\hline \multirow{5}{*}{$\begin{array}{l}\text { Locus of Control Internal } \\
\qquad\left(\mathrm{X}_{1}\right)\end{array}$} & $\mathrm{X} 1.1$ & 0,832 & Valid \\
\hline & $\mathrm{X} 1.2$ & 0,832 & Valid \\
\hline & $\mathrm{X} 1.3$ & 0,757 & Valid \\
\hline & $\mathrm{X} 1.4$ & 0,802 & Valid \\
\hline & $\mathrm{X} 2.1$ & 0,807 & Valid \\
\hline \multirow{7}{*}{$\begin{array}{l}\text { Locus of Control Eksternal } \\
\qquad\left(\mathrm{X}_{2}\right)\end{array}$} & $\mathrm{X} 2.2$ & 0,812 & Valid \\
\hline & $\mathrm{X} 2.3$ & 0,829 & Valid \\
\hline & $\mathrm{X} 2.4$ & 0,778 & Valid \\
\hline & $\mathrm{X} 3.1$ & 0,775 & Valid \\
\hline & $\mathrm{X} 3.2$ & 0,798 & Valid \\
\hline & $\mathrm{X} 3.3$ & 0,887 & Valid \\
\hline & $\mathrm{X} 3.4$ & 0,824 & Valid \\
\hline Budaya Organisasi berbasis & $\mathrm{X} 3.5$ & 0,849 & Valid \\
\hline \multirow[t]{5}{*}{ Tri Hita Karana $\left(\mathrm{X}_{3}\right)$} & X3.6 & 0,815 & Valid \\
\hline & $\mathrm{X} 3.7$ & 0,911 & Valid \\
\hline & $\mathrm{X} 3.8$ & 0,863 & Valid \\
\hline & X3.9 & 0,707 & Valid \\
\hline & $\mathrm{X} 3.10$ & 0,776 & Valid \\
\hline \multirow{2}{*}{$\begin{array}{c}\text { Budaya Organisasi berbasis } \\
\text { Tri Hita Karana }\left(\mathrm{X}_{3}\right)\end{array}$} & X3.11 & 0,863 & Valid \\
\hline & X3.12 & 0,895 & Valid \\
\hline \multirow{11}{*}{$\begin{array}{l}\text { Kinerja Badan } \\
\text { LPD (Y) }\end{array}$} & Y1 & 0,892 & Valid \\
\hline & $\mathrm{Y} 2$ & 0,798 & Valid \\
\hline & Y3 & 0,919 & Valid \\
\hline & Y4 & 0,878 & Valid \\
\hline & Y5 & 0,895 & Valid \\
\hline & Y6 & 0,889 & Valid \\
\hline & Y7 & 0,898 & Valid \\
\hline & Y8 & 0,864 & Valid \\
\hline & Y9 & 0,882 & Valid \\
\hline & Y10 & 0,874 & Valid \\
\hline & Y11 & 0,746 & Valid \\
\hline
\end{tabular}


Valid

Sumber : Data diolah, 2017

Uji reliabilitas digunakan untuk menilai apakah ketepatan jawaban dari kuesioner masih dapat digunakan pada satu periode dengan periode lainnya. Hasil uji reliabilitas dapat dilihat pada Tabel 4. Berdasarkan data pada Tabel 4 dapat dilihat bahwa nilai cronbach's alpha dari setiap variable $\geq 0,60$. Hal ini berarti instrumen yang digunakan sudah reliabel.

Tabel 4.

Hasil Uji Reliabilitas

\begin{tabular}{lcc}
\hline \multicolumn{1}{c}{ Variabel } & Cronbach's Alpha & Keterangan \\
\hline $\begin{array}{l}\text { Locus of Control Internal } \\
\left(\mathrm{X}_{1}\right)\end{array}$ & 0,820 & Reliabel \\
$\begin{array}{l}\text { Locus of Control Eksternal } \\
\left(\mathrm{X}_{2}\right)\end{array}$ & 0,821 & Reliabel \\
$\begin{array}{l}\text { Budaya Organisasi berbasis } \\
\text { Tri Hita Karana }\left(\mathrm{X}_{3}\right)\end{array}$ & 0,959 & Reliabel \\
$\begin{array}{l}\text { Kinerja Badan Pengawas } \\
\text { LPD }(\mathrm{Y})\end{array}$ & 0,970 & Reliabel \\
\hline
\end{tabular}

Sumber : Data diolah, 2017

Penelitian ini menggunakan uji Kolmogorov-Smirnov untuk menguji uji normlitas data. Model regresi yang baik adalah data yang terdistribusi normal atau mendekati normal. Data berdistribusi normal apabila nilai K-S 2-tailed >0,05, untuk hasilnya dapat dilihat pada Tabel 5 .

Tabel 5.

Hasil Uji Normalitas Data (Kolmogorov-Smirnov Test)

\begin{tabular}{llr}
\hline & & Unstandardized Residual \\
\hline $\mathrm{N}$ & & 72 \\
Normal Parameters $^{a}$ & Mean & .0000000 \\
& Std. Deviation & 5.48465290 \\
Most Extreme & Absolute & .081 \\
$\quad$ Differences & Positive & .076 \\
& Negative & -.081 \\
Kolmogorov-Smirnov Z & & .690 \\
Asymp. Sig. (2-tailed) & & .727 \\
Sumber $:$ Data Diolah, 2017 & &
\end{tabular}


Ni Luh Yuli Sudiartini dan Ni Putu Sri Harta Mimba. Pengaruh...

Berdasarkan Tabel 5 dapat dilihat bahwa nilai Sig (2-tailed) adalah sebesar 0,727 > 0,05 maka dapat disimpulkan bahwa variabel-variabel yang digunakan dalam penelitian telah berdistribusi normal sehingga layak untuk diuji.

Hubungan multikolinearitas antara variabel bebas yang satu dengan lainnya dapat dilihat dengan melakukan uji multikolinearitas. Model regresi dikatakan bebas multikolinearitas apabila memiliki nilai VIF $<10$ dan angka tolerance $>0,10$, untuk hasilnya dapat dilihat pada Tabel 6.

Tabel 6.

Hasil Uji Multikolinearitas

\begin{tabular}{lcc}
\hline \multicolumn{1}{c}{ Variabel } & Tolerance & VIF \\
\hline Locus of Control Internal & 0,730 & 1,370 \\
Locus of Control Eksternal & 0,788 & 1,269 \\
Budaya Organisasi berbasis Tri Hita Karana & 0,691 & 1,447 \\
\hline
\end{tabular}

Sumber : Data Diolah, 2017

Berdasarkan Tabel 6 dapat dilihat bahwa masing-masing variabel memiliki nilai $\mathrm{VIF}<10$ dan nilai tolerance $>0,10$ maka dapat dikatakan bahwa tidak terjadi hubungan multikolinearitas antar variabel bebas dalam penelitian ini.

Ketidaksamaan varian dari residual satu pengamatan ke pengamatan lainnya pada model regresi dapat dilihat dengan melakukan uji heteroskedastisitas. Uji Glejser dilakukan untuk melakukan pengujian heteroskedastisitas. Model regresi dikatakan bebas dari heteroskedastisitas apabila memiliki nilai signifikansi masing-masing variabel > 0,05, untuk hasilnya dapat dilihat pada Tabel 7 .

Tabel 7.

Hasil Uji Heteroskedastisitas

\begin{tabular}{lcc}
\hline \multicolumn{1}{c}{ Variabel } & Koefisien t & Sig. \\
\hline Locus of Control Internal & $-0,801$ & 0,426 \\
Locus of Control Eksternal & $-0,679$ & 0,500 \\
Budaya Organisasi berbasis Tri Hita Karana & $-0,458$ & 0.649 \\
\hline Sumber : Data Diolah, 2017 & &
\end{tabular}


Berdasarkan Tabel 7 dapat dilihat bahwa masing-masing variabel memiliki nilai signifikansi > 0,05 maka dapat dikatakan bahwa model regresi yang digunakan dalam penelitian ini bebas dari heteroskedastisitas.

Untuk mengetahui pengaruh locus of control internal $\left(\mathrm{X}_{1}\right)$, locus of control eksternal $\left(\mathrm{X}_{2}\right)$, dan budaya organisasi berbasis tri hita karana $\left(\mathrm{X}_{3}\right)$ pada kinerja badan pengawas LPD (Y) digunakan model analisis data yakni regresi linier berganda, untuk hasilnya dapat dilihat pada Tabel 8 .

Tabel 8.

Hasil Analisis Regresi Linier Berganda

\begin{tabular}{lccc}
\hline \multicolumn{1}{c}{ Variabel } & $\begin{array}{c}\text { Koefisien } \\
\text { Regresi }\end{array}$ & t-hitung & Signifikansi \\
\hline Constant & 9,033 & 1,887 & 0,063 \\
Locus of Control Internal & 1,049 & 4,344 & 0,000 \\
Locus of Control Eksternal & $-0,590$ & $-2,542$ & 0,013 \\
Budaya Organisasi berbasis Tri Hita & 0,561 & 6,984 & 0,000 \\
Karana & 0,723 & & \\
$R_{\text {Square }}$ & 0,711 & & \\
Adjusted $R_{\text {Square }}$ & 59,177 & & \\
F $_{\text {hitung }}$ & 0,000 & & \\
Signifikasi & & & \\
Sumber: Data Diolah, 2017 & & &
\end{tabular}

Sumber: Data Diolah, 2017

Berdasarkan Tabel 8 analisa regresi linier berganda terhadap variabel bebas dan variabel terikat diperoleh dari koefisien $\alpha=9,033$ dan nilai koefisien $\beta_{1}=1,049, \beta_{2}=-$ $0,590, \beta_{3}=0,561$. Berdasarkan hasil penelitian tersebut, maka model persamaan regresi linier berganda akan tampak sebagai berikut:

$$
Y=9,033+1,049 X_{1}-0,590 X_{2}+0,561 X_{3}
$$

Persamaan regresi tersebut dapat dijelaskan sebagai berikut. 1) Nilai konstanta 9,033 artinya bila locus of control internal $\left(\mathrm{X}_{1}\right)$, locus of control eksternal $\left(\mathrm{X}_{2}\right)$, budaya organisasi berbasis tri hita karana $\left(\mathrm{X}_{3}\right)$, sama dengan nol maka kinerja badan pengawas LPD di Kabupaten Karangasem adalah sebesar 9,033. 2) Nilai koefisien regresi locus of control internal $\left(\mathrm{X}_{1}\right)=1,049$, artinya apabila locus of control internal $\left(\mathrm{X}_{1}\right)$ naik sebesar 
Ni Luh Yuli Sudiartini dan Ni Putu Sri Harta Mimba. Pengaruh...

satu satuan sementara locus of control eksternal $\left(\mathrm{X}_{2}\right)$ dan budaya organisasi berbasis tri hita karana $\left(\mathrm{X}_{3}\right)$ diasumsikan konstan maka kinerja badan pengawas LPD di Kabupaten Karangasem akan meningkat sebesar 1,049. 3) Nilai koefisien regresi locus of control eksternal $\left(\mathrm{X}_{2}\right)=-0,590$, artinya apabila locus of control eksternal $\left(\mathrm{X}_{2}\right)$ naik sebesar satu satuan sementara locus of control internal $\left(\mathrm{X}_{1}\right)$ dan budaya organisasi berbasis tri hita karana $\left(\mathrm{X}_{3}\right)$ diasumsikan konstan maka kinerja badan pengawas LPD di Kabupaten Karangasem akan menurun sebesar -0,590. 4) Nilai koefisien regresi budaya organisasi berbasis tri hita karana $\left(\mathrm{X}_{3}\right)=0,561$, artinya apabila budaya organisasi berbasis tri hita karana $\left(\mathrm{X}_{3}\right)$ naik sebesar satu satuan sementara locus of control internal $\left(\mathrm{X}_{1}\right)$ dan locus of control eksternal $\left(\mathrm{X}_{2}\right)$ diasumsikan konstan maka badan pengawas LPD di Kabupaten Karangasem akan meningkat yaitu sebesar 0,561.

Untuk memprediksi dan menjawab rumusan masalah suatu penelitian dapat diketahui melalui uji kelayakan model (Uji F). Kriteria pengujian yang digunakan adalah dengan membandingkan nilai signifikansi uji $\mathrm{F}$ dengan taraf signifikansi $5 \%$. Apabila nilai signifikansi uji $\mathrm{F}<$ taraf signifikansi $(0,05)$ maka model regresi yang digunakan layak untuk sebuah prediksi. Tabel 8 menunjukkan nilai dari hasil uji $\mathrm{F}$ adalah sebesar 59,177 dengan signifikansi adalah sebesar 0,000. Karena nilai signifikansi sebesar 0,000 lebih kecil dari $\alpha(0,05)$ artinya bahwa model yang digunakan dalam penelitian ini adalah layak.

Berdasarkan tabel 8 menunjukkan bahwa nilai Adjusted R square adalah sebesar 0,711. Hal ini berarti sebanyak $71,1 \%$ variasi kinerja badan pengawas LPD mampu dijelaskan oleh variasi dari variabel locus of control internal, locus of control eksternal dan budaya organisasi berbasis tri hita karana sedangkan sisanya sebesar $28,9 \%(100 \%$ - 71,1\% ) dijelaskan oleh variabel lain diluar model. 
Uji t dilakukan untuk mengetahui seberapa besar pengaruh variabel independen terhadap variabel dependen secara parsial. Uji t dilakukan dengan membandingkan nilai signifikansi yang dihasilkan dengan $\alpha(0,05)$. Berdasarkan Tabel 8 maka dapat diketahui bahwa nilai signifikansi untuk variabel locus of control internal adalah sebesar $0,000<$ 0,05 dengan koefisien regresi bernilai positif sebesar 1,049. Berdasarkan hal tersebut maka dapat disimpulkan bahwa $\mathrm{H}_{0}$ ditolak dan $\mathrm{H}_{1}$ diterima. Ini berarti variabel locus of control internal berpengaruh positif dan signifikan pada kinerja badan pengawas LPD atau dengan kata lain semakin tinggi locus of control internal, maka kinerja badan pengawas LPD akan semakin meningkat. Hasil penelitian ini konsisten dengan penelitian Ayudiati (2010), Gevi (2014), dan Sanjiwani dan Wisadha (2015) yang menyatakan bahwa locus of control internal berpengaruh pada kinerja auditor. Badan pengawas LPD yang memiliki locus of control internal akan yakin dengan kemampuan dirinya untuk menyelesaikan pekerjaan-pekerjaan mereka sehingga menimbulkan rasa kepuasan kerja dan akan meningkatkan kinerjanya. Apabila badan pengawas LPD memiliki kemampuan, serta minat dan bakat yang tinggi dari dalam dirinya maka akan memacu kepercayaan dirinya dalam meningkatkan kinerjanya.

Berdasarkan tabel 8, maka dapat diketahui bahwa nilai signifikansi untuk variabel locus of control eksternal adalah sebesar 0,013 < 0,05 dengan koefisien regresi bernilai negatif sebesar $-0,590$. Berdasarkan hal tersebut maka dapat disimpulkan bahwa $\mathrm{H}_{0}$ ditolak dan $\mathrm{H}_{2}$ diterima. Ini berarti variabel locus of control eksternal berpengaruh negatif dan signifikan pada kinerja badan pengawas LPD atau dengan kata lain semakin meningkat locus of control eksternal maka kinerja badan pengawas LPD akan semakin menurun. Hasil penelitian ini konsisten dengan penelitian Kusnadi (2015) dan Rita, et al (2016) yang menyatakan bahwa locus of control eksternal berpengaruh 
Ni Luh Yuli Sudiartini dan Ni Putu Sri Harta Mimba. Pengaruh...

negatif pada kinerja auditor. Badan pengawas LPD yang memiliki locus of control eksternal akan lebih mudah merasa terancam dan tidak berdaya, maka strategi yang dipilih cenderung reaktif. Apabila badan pengawas LPD lebih mempercayai nasib atau keberuntungan daripada kemampuan yang dimiliki, hal tersebut akan mempengaruhi kinerjanya yang dapat mengalami penurunan.

Berdasarkan tabel 8, maka dapat diketahui bahwa nilai signifikansi untuk variabel budaya organisasi berbasis tri hita karana adalah sebesar 0,000 $<0,05$ dengan koefisien regresi bernilai positif sebesar 0,561. Berdasarkan hal tersebut maka dapat disimpulkan bahwa $\mathrm{H}_{0}$ ditolak dan $\mathrm{H}_{3}$ diterima. Ini berarti variabel budaya organisasi berbasis tri hita karana berpengaruh positif dan signifikan pada kinerja badan pengawas LPD atau dengan kata lain semakin meningkat budaya organisasi berbasis tri hita karana maka kinerja badan pengawas LPD akan semakin meningkat.

Hasil penelitian ini konsisten dengan penelitian Saputra (2012) dan Mustikayani dan Dwirandra (2016) yang menyatakan bahwa budaya organisasi berpengaruh pada kinerja. Kesesuaian budaya organisasi berbasis tri hita karana yang diterapkan LPD dengan perilaku badan pengawas LPD memiliki kemampuan untuk meningkatkan kinerjanya, karena budaya organisasi ditetapkan demi mewujudkan tujuan dari organisasi. Penerapan nilai-nilai budaya tri hita karana dalam LPD mampu memotivasi badan pengawas LPD untuk bekerja lebih baik sehingga akan meningkatkan kinerjanya.

\section{SIMPULAN}

Berdasarkan analisis data dan pembahasan yang telah dipaparkan sebelumnya, dapat disimpulkan bahwa dari tiga hipotesis yang diajukan, semua hipotesis diterima. Adapun kesimpulan dari hasil penelitian yang dilakukan adalah sebagai berikut : 1) Locus of control internal berpengaruh positif pada kinerja badan pengawas LPD. Hal ini 
menunjukkan bahwa semakin tinggi locus of control internal, maka semakin tinggi kinerja yang dimiliki badan pengawas LPD. 2) Locus of control eksternal berpengaruh negatif pada kinerja badan pengawas LPD. Hal ini menunjukkan bahwa semakin tinggi locus of control eksternal, maka kinerja badan pengawas LPD akan mengalami penurunan. 3) Budaya organisasi berbasis tri hita karana berpengaruh positif pada kinerja badan pengawas LPD. Hal ini menunjukkan bahwa semakin tinggi atau kuat budaya organisasi berbasis tri hita karana yang diaplikasikan, maka akan meningkatkan kinerja dari badan pengawas LPD.

Berdasarkan simpulan atas pembahasan dan analisis tersebut maka dapat disarankan sebagai berikut : 1) Hasil penilaian variabel locus of control internal dan penerapan budaya organisasi berbasis tri hita karana merupakan salah satu faktor pendorong tercapainya kinerja badan pengawas LPD yang lebih baik. Oleh karena itu, sebaiknya badan pengawas LPD selalu menjaga locus of control internal yang dimiliki dan meningkatkan penerapan budaya organisasi berbasis tri hita karana. Sedangkan untuk penilaian variabel locus of control eksternal yang terbukti menurunkan kinerja, sebaiknya badan pengawas LPD meminimalisir kepercayaan terhadap faktor luar seperti nasib maupun keberuntungan yang menentukan keberhasilannya. 2) Bagi peneliti selanjutnya diharapkan dapat melakukan penelitian pada LPD di daerah Bali lainnya sehingga menjadi lebih tergeneralisasi. Selain itu dapat juga mempertimbangkan faktorfaktor lain yang mempengaruhi kinerja badan pengawas LPD seperti pengalaman kerja dan komitmen organisasi. Untuk budaya organisasi, peneliti selanjutnya dapat mempertimbangkan budaya lokal yang berkembang dikabupaten tersebut sebagai budaya organisasi yang diadopsi. 


\section{REFERENSI}

Adewale, O. O., \& Anthonia, A. A. (2013). Impact of Organizational Culture on Human Resource Practices: A Study of Selected Nigerian Private Universities. Journal of Competitiveness. 5(4) : pp: 115-133.

Adiputra, I Made Pradana, Anantawikrama Tungga Atmadja and Komang Adi Kurniawan Saputra. 2014. Culture of Tri Hita Karana as Moderating of Locus of Control on the Performance of Internal Auditor. (Studies in the Office of the Provincial Inspectorate in Bali). Research Journal of Finance and Accounting. 5(22) : pp: 27-35.

Alvaro Amaral Menezez. 2008. Analisis Dampak Locus of Control terhadap Kinerja dan Kepuasan Kerja Internal Auditor (Penelitian terhadap Internal Auditor di Jawa Tengah). Tesis. Universitas Diponegoro.

Ayudiati, Soraya Eka. 2010.Analisis Pengaruh Locus of Control Terhadap Kinerja dengan Etika Kerja Islam sebagai variable moderating (studi pada karyawan tetap Bank Jateng Semarang).Skripsi.Undip.

Bima Bayu Aji. 2010. Analisis Dampak Locus of Control pada Tekanan Kerja, Kepuasan Kerja, dan Kinerja Auditor Internal. Skripsi.Universitas Diponegoro.

Bunga Nur Juliningtyas. 2012. Pengaruh Locus of Control, Gaya Kepemimpinan dan Komitmen Organisasi pada Kinerja Auditor. Accounting Analysis Journal. (1)1 : pp: 7-14.

Ceacilia Srimindarti, Sunarto, and Listyorini Wahyu Widati. 2015. The Effects of Locus of Control and Organizational Commitment to Acceptance of Dysfunctional Audit Behavior Based on The Theory of Planned Behavior. International Journal of Business, Economics, and Law. University of Stikubank, Semarang. 7(1) : pp: 2735 .

Ebru Yildiz. 2014. A Study on the Relationship between Organizational Culture and Organizational Performance and a Model Suggestion. International Journal of Research in Business and Social Science (IJRBS). Sakarya University. 3(4) : pp: 52-67.

Ehtesham, Ul Mujeeb, Tahir Masood Muhammad, and Shakil Ahmad Muhammad. 2011. Relationship between Organizational Culture and Performance Management Practices : A Case of University in Pakistan. Journal of Competitivenes. 4 : pp: 78-86.

Engko, Cecilia dan Gundono. 2007. Pengaruh Kompleksitas Tugas dan Locus of Control Terhadap Hubungan Antara Gaya Kepemimpinan dan Kepuasan Kerja Auditor. Simposium Nasional Akuntansi X, AMKP-08, Makassar. 
Gevi Nur Aripriyanti. 2014. Pengaruh Komitmen Organisasi, Locus of Control, dan Kompleksitas Tugas terhadap Kinerja Auditor Internal (Survei Penelitian pada Perusahaan-perusahaan BUMN di Kota Bandung). Skripsi. Fakultas Ekonomi Universitas Widyatama.

Gunawan, Ketut. 2011. Peran Falsafah Tri Hita Karana bagi Pertumbuhan dan Kinerja Lembaga Perkreditan Desa (LPD) di Bali. 2011. Analisis Manajemen.5(2) : pp : 23-36.

Kurt A. April, Babar Dharani, and Kai Peters. 2012. Impact of Locus of Control Expectancy on Level of Well-Being. Review of European Studies.University of Cape Town, South Africa. 4(2) : pp: 124-137.

Kusnadi, I Made Gheby. 2015. Pengaruh Profesionalisme dan Locus of Control terhadap Kinerja Auditor di Kantor Akuntan Publik Provinsi Bali. Skripsi. Fakultas Ekonomi dan Bisnis. Universitas Udayana.

Lubis, Arfan Ikhsan. 2009. Akuntansi Keperilakuan. Medan; Penerbit salemba Empat.

Margie Christanty Poluan, Julie J. Sondakh, dan Herman Karamoy. 2016. Pengaruh Locus of Control, Self Esteem, Equity Sensitivity Auditor Internal terhadap Kualitas Audit dengan Gender sebagai variabel Mediasi. Jurnal Riset Akuntansi dan Auditing “Goodwill”. 7(1) : pp: 43-55.

Muslim Alkautsar. 2014. Locus of Control, Commitment Professional, and Dysfunctional Audit Behaviour. International Journal of Humanities and Management Sciencies (IHMS). 2(1): pp: 35-38.

Mustikayani, Ni Luh Putu Desy dan A.A.N.B Dwirandra. 2016. Budaya Tri Hita Karana sebagai Pemoderasi Kompleksitas Tugas dan Tekanan Waktu terhadap Kinerja Auditor. E-journal Akuntansi Universitas Udayana. 16(2) : pp : 15441573.

Nasrullah Dali dan Arifuddin Mas'ud. 2014. The Impact of Professionalism, Locus of Control, and Job Satisfaction on Auditors' Performance: Indonesian Evidence. International Journal of Business and Management Invention. 3(10), pp: 63-73.

Armanu, Margono Setiawan, and Solimun. 2013. Professionalism and Locus of Control Influence On Job Satisfaction Moderated by Spirituality at Work and Its Impact on Performance Auditor. International Journal of Business and Management Invention. 2(10) : pp: 1-11.

Nenni Yulistiyani. 2014. Pengaruh Independensi Auditor, Gaya Kepemimpinan, Komitmen Organisasi, dan Budaya Organisasi terhadap Kinerja Auditor (Studi Empiris pada Kantor Akuntan Publik di Surakarta dan Yogyakarta). Artikel Publikasi Ilmiah.

Peraturan Daerah Bali No. 4 tahun 2012 tentang Perubahan Atas Peraturan Daerah Provinsi Bali Nomor 8 Tahun 2002 Tentang Lembaga Perkreditan Desa. 
Peraturan Gubernur Bali No 11 Tahun 2013 tentang Petunjuk Pelaksanaan Peraturan Daerah Provinsi Bali Nomor 8 Tahun 2002 Tentang Lembaga Perkreditan Desa Sebagaimana Telah Diubah Beberapa Kali Terakhir Dengan Peraturan Daerah Provinsi Bali Nomor 4 Tahun 2012 Tentang Perubahan Kedua Atas Peraturan Daerah Provinsi Bali Nomor 8 Tahun 2002 Tentang Lembaga Perkreditan Desa.

Pratiwi Hutahusut, Syauffa dan Reskino. 2016. Pengaruh Budaya Organisasi, Pelaksanaan Tanggung Jawab, Otonomi Kerja dan Ambiguitas Peran Terhadap Kinerja Auditor. Jurnal Ilmu Akuntansi. 9(1) : pp: 55-72.

Putra, I Gusti Agung Mahendra dan Made Yenni Latriani. 2016. Pengaruh Locus of Control dan Komitmen Profesional pada Kinerja Auditor Internal. E-Jurnal Akuntansi Universitas Udayana. 17 (3) : pp : 1808-1833.

Putri, Ni Made Dwiyana Rasuma. 2015. Analisis Perbedaan Tingkat Kepuasan Kerja Auditor pada Locus of Control Internal dan Eksternal. Jurnal Akuntansi Universitas Udayana. 13 (1) : pp : 68-83.

Rana Ozen Kutanis, Muammer Mesci and Zeynep Ovdur. 2011. The Effect of Locus of Control on Learning Performance : A Case of an Academic Organization. Journal of Economic and Social Studies. 1(2) : pp: 113-136.

Riana, I Gede. 2010. Dampak Penerapan Kultur Lokal Tri Hita Karana terhadap Orientasi Kewirausahaan dan Orientasi Pasar serta Konsekuensinya pada Kinerja Usaha (Studi pada IKM Kerajinan Perak di Bali). Disertasi Program Pascasarjana Universitas Brawijaya, Malang.

Rita Anugerah, Rizqa Anita, Ria Nelly Sari and Raisya Zenita. 2016. External Locus of Control and Reduced Audit Quality Behavior: The Mediating Effects of Auditor Performance and Organizational Commitment. Journal of Economics, Business and Management. 4(5) : pp: 353-357.

Rotter, J.B. 1966, "Generalized expectancies for internal versus external control of reinforcement", Psychological Monographs, Vol. 80 (1) : pp : 1-28.

Sanjiwani, Desak Made Putri dan I Gede Suparta Wisadha. 2015. Pengaruh Locus of Control, Gaya Kepemimpinan, dan Komitmen Organisasi pada Kinerja Auditor Kantor Akuntan Publik. E-Jurnal Akuntansi Universitas Udayana. 14(2) : pp: 920-947.

Saputra, Komang Adi Kurniawan. 2012. Pengaruh Locus of Control terhadap Kinerja dan Kepuasan Kerja Internal Auditor dengan Kultur Lokal Tri Hita Karana sebagai Variabel Moderasi. Jurnal Akuntansi Multiparadigma. 3(1) : pp: 86-100.

Sujana, I Ketut, Made Sudarma, and Gugus Irianto. 2014. "Harmoni" as a Performance Appraisal of Village Credit Institution on Bali, Indonesia. Scientific Research Journal (SCIRJ). 2(7) : pp: 1-10. 
Surya, Ida Bagus Ketut. 2014. Pengaruh Budaya Tri Hita Karana terhadap Kinerja Perusahaan dengan Mediasi Kepemimpinan dan Komitmen Organisasional (Studi pada perusahaan Daerah Air Minum di Provinsi Bali). Disertasi. Fakultas Ekonomi dan Bisnis Universitas Brawijaya Malang.

Uddin, Mohammad Jasim, Rumana Huq Luva, and Saad Md. Maroof Hossian. 2013. Impact of Organizational Culture on Employee Performance and Productivity : A Case Study of Telecommunication Sector in Bangladesh. International Journal of Business and Management. Canadian Center of Science and Education. 8(2) : pp: 63-77.

Undang undang No. 1 tahun 2013 tentang Lembaga Keuangan Mikro. Dewan Perwakilan Rakyat Republik Indonesia.

Vishal Mali. 2013. A Study on Locus of Control and Its Impact on Employees' Performance. International Journal of Science and Research (IJSR). 2(12) : pp: 149-151.

Winata, IGK Adi, Wayan Windia, dan I Wayan Suartana. 2015. Membangun Strategi Operasi melalui Budaya Organisasi berbasis Tri Hita Karana untuk Mencapai Keunggulan Bersaing Berkelanjutan : Kasus pada Lembaga Perkreditan Desa di Kabupaten Buleleng. Jurnal Manajemen Agribisnis. 3(2) : pp: 81-92.

Zubir Syahputra. 2014. Influence of Locus of Control and Organizational Commitment on Job Satisfaction Moderated by Organanizational Culture and Its Impact on Job Performance (Study of Employee's Aceh Local Government). Journal of Economics and Sustainable Development. 5(17) : pp : 104-110. 